Cite this: Phys. Chem. Chem. Phys., 2014, 16, 11017

Received 10th February 2014, Accepted 7th April 2014

DOI: 10.1039/c4cp00597j

www.rsc.org/pccp

\section{Size-selected gold clusters on porous titania as the most "gold-efficient" heterogeneous catalysts}

\author{
Andreas Dollinger, ${ }^{a}$ Lukas Stolch, ${ }^{a}$ Yuan Luo, ${ }^{a}$ Martin Beck, ${ }^{a}$ Christoph H. Strobel, ${ }^{a}$ \\ Matthias Hagner, ${ }^{a}$ Stefan Dilger, ${ }^{b}$ Malin Bein, ${ }^{\mathrm{b}}$ Sebastian Polarz, ${ }^{* \mathrm{~b}}$ \\ Gerd F. Gantefoer, ${ }^{* a}$ Young-Dok Kim ${ }^{c}$ and Sebastian Proch ${ }^{{ }^{a}}$
}

Research on homogeneous and heterogeneous catalysis is indeed convergent and finds subnanometric particles to be at the heart of catalytically active species. Here, monodisperse gold clusters are deposited from the gas phase onto porous titania generating well-defined model systems and the resulting composite materials exhibit a sharp size-dependency on the number of gold atoms per cluster and exceptionally highturnovers toward the bromination of 1,4-dimethoxybenzene are observed. This indicates that the deliberate generation of active centres is of utmost importance for the creation of the most "gold-efficient" catalysts.

\section{Introduction}

In $1985^{1} / 87^{2}$ first subtle clues were found that gold presents an element as valuable for chemists as for jewellers. Today it has become ubiquitous in heterogeneous (epoxidation, ${ }^{3}$ oxidative coupling of anilines, ${ }^{4}$ selective oxidation with dioxygen, ${ }^{5}$ $\mathrm{CO}$ oxidation $^{6}$ ) and homogeneous (a multitude of organic transformations ${ }^{7}$ ) catalysis alike. This in turn leads to a situation where gold as a catalyst has to compete with gold as an investment especially in times of "uncertainty". ${ }^{8}$ So if gold is successfully to be used as a catalyst no gold must be wasted. As per definition the most atom-efficient catalyst system has to consist exclusively of active sites ${ }^{9}$ preferably with only a single metal atom per site. The latter requirement can be fulfilled for molecular catalysts applied in the homogeneous phase, ultimately enzymes. ${ }^{10}$ However, there are natural limits for the application of molecular catalysts, for instance at high process temperatures or in the absence of solvents. Thus, solid-state compounds applied in the heterogeneous state represent a distinct and important class of catalysts. Unfortunately, it is currently out of range to tailor make solid-state catalysts with such high atom-efficiency as described above. Research in this field is vital in particular for heterogeneous gold catalysts.

An interesting connection between molecular and solid-state gold catalysts was revealed by Corma et al. Impressive TONs (turn over numbers), approaching the efficiency of enzymes,

\footnotetext{
${ }^{a}$ Fachbereich für Physik, Universität Konstanz, Universitätsstrasse 10, 78464 Konstanz, Germany. E-mail: gerd.gantefoer@uni-konstanz.de, sebastian.proch@uni-konstanz.de

${ }^{b}$ Fachbereich für Chemie, Universität Konstanz, Universitätsstrasse 10, 78464 Konstanz, Germany. E-mail: sebastian.polarz@uni-konstanz.de

${ }^{c}$ Department of Chemistry, Sungkyunkwan University, Suwon 440-746, Korea
}

have recently been observed for the ester-assisted hydration of alkynes and bromination of aromatics catalysed by $\mathrm{AuCl}$ in solution. However, Corma et al. uncovered a deeper understanding regarding the active sites of $\mathrm{Au}(+1)$ and $\mathrm{Au}(+3)$ catalysts, as it was found that subnanometric gold clusters (1-10 atoms) are responsible for catalytic activity. ${ }^{11}$ These findings are convergent with the invaluable work of Hutchings et al. on heterogeneous gold catalysts showing that $\mathrm{CO}$ oxidation is actually catalysed by subnanometric bilayer clusters (1-10 atoms) and larger particles merely act as spectator species. ${ }^{6}$ The group of Corma et al. also tried to transfer their findings to heterogeneous catalysis by preparing $\mathrm{Au}_{5}$ - and $\mathrm{Au}_{8}$-PAMAM (poly[amidoamine]) ${ }^{12}$ and used them in the above reactions. Unfortunately results obtained were TONs two orders of magnitude lower compared with homogenous clusters in solution, leaving a TON of $10^{2}$ for the bromination of 1,4-dimethoxybenzene with $N$-bromosuccinimide (NBS). ${ }^{11}$ This drop in TON is most likely due to encapsulation of clusters by the PAMAM dendrimer template. However, dendrimer template directed synthesis routes ${ }^{12,13}$ are currently the only wet chemical methods to make size-selected metal clusters, apart from "magic" number clusters, we are aware of.

Previously, work on size-selected gold clusters deposited on $\mathrm{TiO}_{2}(110)$ single crystals under UHV conditions found an extreme size-dependent reactivity towards the oxidation of $\mathrm{CO}$, while $\mathrm{Au}_{5}$ is almost inert $\mathrm{Au}_{6}$ and $\mathrm{Au}_{7}$ are very active. ${ }^{14,15}$ While catalytic activity serves as a valuable probe for conservation of sizedependent properties of soft-landed clusters $(<1 \mathrm{eV}$ per atom) XPS measurements of as-deposited clusters gave rise to the same binding energy of $84.7 \mathrm{eV}\left(\mathrm{Au} 4 \mathrm{f}_{7 / 2}\right)$ for all $\mathrm{Au}_{n}$ ranging from $n=1$ to $7 .{ }^{15}$ Recently the authors have carried out TPD experiments towards $\mathrm{CO}$ oxidation activity on $\mathrm{Au}_{n} /\left(\mathrm{TiO}_{2}\right)_{93} / \mathrm{HOPG}(n=5$ to 8$)$ composite materials demonstrating that size-dependent properties of catalytic activity observed in single-crystal experiments 


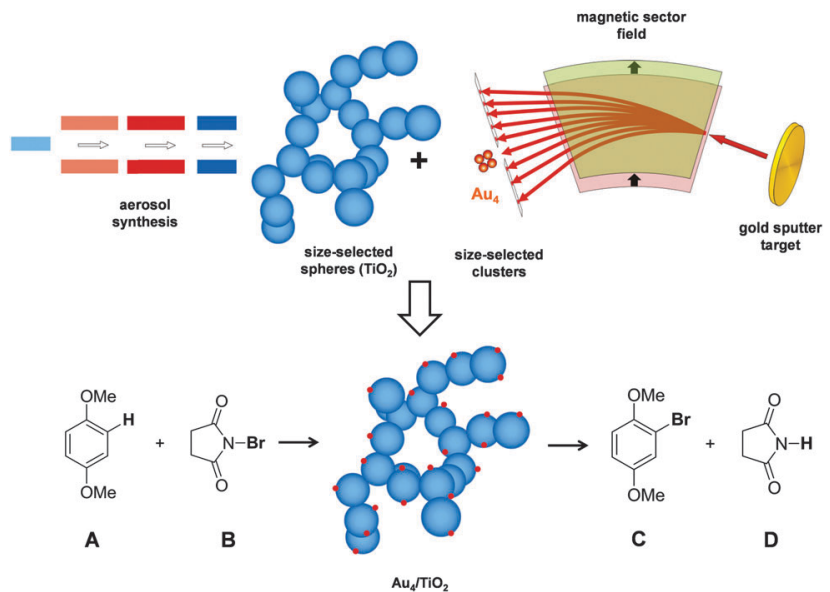

Scheme 1 Example of the synthesis of a composite material consisting of size-selected clusters on a highly porous, aerogel-like $\mathrm{TiO}_{2}$, here $\mathrm{Au}_{4} / \mathrm{TiO}_{2}$, and its application in catalysis.

were preserved on these nanoparticle like $\mathrm{TiO}_{2}$-clusters (diameter approx. $1 \mathrm{~nm}$ ). Moreover, results indicate that only $\mathrm{Au}_{6}$ and $\mathrm{Au}_{7}$ are active for $\mathrm{CO}$ oxidation, creating a situation where coincidental formation of "active species" on high-surface area $\mathrm{TiO}_{2}$ supports is very unlikely. ${ }^{16}$ These findings led us to believe that size-dependent properties of gold clusters can be probed in real catalytic environments on relevant supports like porous titania. Especially in the light that Corma et al. discovered TONs of $10^{7.11}$ A realistic value of deposited clusters within a reasonable time frame and without excessive consumption of gold sputter targets (see Scheme 1) is about $10^{13}$. This should give rise to the formation of $10^{20}$ product molecules, corresponding to millimolar quantities which are easily detected by gas-chromatographic methods.

Here, we suggest size-selected cluster deposition as a tool to deliberately create active sites on virtually any catalyst support by purely applying gas phase methods (Scheme 1), which is at the heart of the vision of "nanocatalysis". ${ }^{17}$ Highly porous, highly crystalline metal oxide materials can be produced in a controlled fashion facilitating an aerosol-assisted method. ${ }^{18-20}$ During this process, nanosized primary particles form, which then agglomerate into fractal, highly porous networks. The advantage of these aerogellike materials is that particles dispersed in the gas-phase are able to penetrate easily and very deep into the porous framework. Thus, in a second step metal clusters are mass-selected in a magnetic sector field and are soft-landed (size-selected clusters) on the metal oxide support, hereby the masses can be selected on an atom-by-atom basis (cluster deposition setup is described in the experimental section). A particular system $\mathrm{Au}_{n} / \mathrm{TiO}_{2}$ has been chosen for three reasons: (i) gold is very oxidation resistant and can be transferred from ultra-high vacuum (UHV) to ambient conditions without changes in chemical integrity; ${ }^{21-24}$ (ii) gold particles on titania exhibit strong metal support interaction (SMSI); ${ }^{25}$ and (iii) it has been shown that $\mathrm{Au} / \mathrm{TiO}_{2}$ is a superior catalyst for homocoupling of iodobenzene compared to $\mathrm{Au}_{n}$-PAMAM. ${ }^{26}$ Here it will be shown that size-selected clusters do not only act as model systems for catalysis under UHV conditions but also as very efficient catalysts for the bromination of 1,4-dimethoxybenzene in solution.

\section{Experimental}

Since this work contains methodology of heterogeneous catalysis in solution and cluster deposition both approaches are explained in detail in the following section.

\section{General experimental section}

\section{Analytical methods}

XPS (X-ray photoelectron spectroscopy). XPS spectra have been recorded using an Omicron EA 125 CHA (concentric hemispherical analyzer) with a base pressure in the main chamber of $\approx 5 \times$ $10^{-10}$ mbar using the $\mathrm{Mg} \mathrm{K}_{\alpha}$-line $(1253.6 \mathrm{eV})$. Peak fitting was done via CASA XPS and a Gaussian-Lorentzian fit (GL30), the peak separation for $\mathrm{Au} 4 \mathrm{f}$ was kept at $\Delta=3.67 \mathrm{eV} .^{27}$

SEM (scanning electron microscopy). The highly porous $\mathrm{TiO}_{2}-$ layer has been characterized using a Zeiss Cross Beam 1540 XB, which is a combination of a Scanning Electron Microscope (SEM) and a Focused Ion Beam (FIB). To determine the thickness a crosssection was cut into the layer using the FIB and analyzed by SEM.

TEM (transmission electron microscopy). Micrographs have been obtained by dip coating $\mathrm{TiO}_{2}$ primary particles $(13.4 \mathrm{~nm})$ onto copper/carbon grids, deposition of $\mathrm{Au}_{120}$ clusters at a cluster current of $200 \mathrm{pA}$ for $2 \mathrm{~h}$, and subsequent investigation within a Jeol ARM instrument.

GC/MS (gas chromatography/mass spectrometry). GC measurements were done using an Agilent 7890A machine equipped with a Zebron ZB-5MS column with a length of $30 \mathrm{~m}$, an inner diameter of $0.25 \mathrm{~mm}$ and a film thickness of $0.25 \mu \mathrm{m}$. The temperature program for GC measurements was as follows: (i) $50{ }^{\circ} \mathrm{C}$ held for $1 \mathrm{~min}$; (ii) the temperature is raised to $280{ }^{\circ} \mathrm{C}$ at a rate of $30{ }^{\circ} \mathrm{C} \mathrm{min}{ }^{-1}$; (iii) the temperature is held at $280{ }^{\circ} \mathrm{C}$ for another $3 \mathrm{~min}$. MS measurements were performed on an Agilent 5975C apparatus.

\section{Wet chemical methods}

Dip coating of aerogel-like $\mathrm{TiO}_{2}$ onto tantalum backing plates. Aerogel-like $\mathrm{TiO}_{2}(1 \mathrm{mg})$ is suspended in $0.2 \mathrm{ml}$ of ethanol (pA) and dip coated onto a $10 \mathrm{~mm} \times 10 \mathrm{~mm}$ tantalum backing plate. The ethanol is allowed to evaporate from the sample at room temperature and then it is introduced into the deposition chamber of the cluster deposition apparatus.

Bromination of 1,4-dimethoxybenzene. 1,4-Dimethoxybenzene (A, $0.5 \mathrm{mmol}, 69 \mathrm{mg}$, see Scheme 1) and $N$-bromosuccinimide (B, NBS, $0.5 \mathrm{mmol}, 89 \mathrm{mg}$ ) are placed inside a $5 \mathrm{ml}$ vial and dissolved in $2 \mathrm{ml}$ dichloroethane. The catalyst (blank, AuCl [5 mg], $\mathrm{HAuCl}_{4}[5 \mathrm{mg}], \mathrm{TiO}_{2}[5 \mathrm{mg}], \mathrm{Au}_{4} / \mathrm{TiO}_{2}[1 \mathrm{mg}], \mathrm{Au}_{7} / \mathrm{TiO}_{2}$ [1 mg], $\mathrm{Au}_{8} / \mathrm{TiO}_{2}$ (a) [1 mg], $\mathrm{Au}_{8} / \mathrm{TiO}_{2}$, (b) [1 mg], Au $1 \mathrm{ATiO}_{2}$ [1 mg], $\mathrm{Au}_{120} / \mathrm{TiO}_{2}$ [1 mg]) was added, the vial sealed with a cap, and the reaction stirred for $24 \mathrm{~h}$ at room temperature. After that time period had elapsed the vial was reopened and dodecane $(0.5 \mathrm{mmol}, 64 \mu \mathrm{l})$ was added to the mixture as internal standard for GC/MS, the mixture was then filtered, and diluted in hexane prior to the actual GC/MS measurement. ${ }^{11}$

In order to obtain the number of generated molecules of 1-bromo-2,5-dimethoxybenzene (C, see Scheme 1) GC calibration 
with the temperature ramp mentioned above has been done. Therefore, $1 \mathrm{mmol}$ of dodecane (internal standard) and $1 \mathrm{mmol}$ are dissolved in hexane and the corresponding chromatogram is measured. The GC/MS method allows unambiguous identification of both substances without having to obtain chromatograms of isolated compounds first. The peak areas of $\mathbf{C}$ and dodecane within the chromatogram are linked by the following relationship: $\frac{A_{\text {dodecane }}}{n_{\text {dodecane }}}=f_{\text {calibration }} \frac{A_{\mathrm{c}}}{n_{\mathrm{c}}}$, where $A$ is the area and $n$ the number of moles of the respective substances. This procedure yields the calibration factor $f_{\text {calibration }}=\frac{A_{\text {dodecane }}}{A_{\mathrm{c}}}=6.43$. With this known factor the amount of $\mathbf{C}$ within the solution after reaction can be determined by adding a known amount of dodecane. The TONs reported in Table 2 are obtained by dividing the number of product molecules $\mathbf{C}$ over (i) the number of clusters in the catalyst (TON per gold cluster) or (ii) the number of gold atoms in the catalyst (TON per gold atom) given in units $\frac{\text { number of molecules } \mathbf{C}}{\text { number of gold clusters }}$ and $\frac{\text { number of molecules } \mathbf{C}}{\text { number of gold atoms }}$, respectively. The number of clusters/gold atoms is obtained by measuring and integrating the neutralization current during cluster deposition (see below). This number corresponds to the number of clusters/atoms within the catalyst since all materials obtained from deposition are used as reaction catalysts.

\section{Gas-phase methods}

Synthesis of aerogel-like $\mathrm{TiO}_{2}$. The liquid precursor $\mathrm{Ti}\left(\mathrm{O}^{\mathrm{iso}} \mathrm{Pr}\right)_{4}$ is injected into the evaporation zone of the aerosol synthesis setup using a syringe pump from KD Scientific model KS200. The addition of the precursor to the evaporation zone (EZ) via the syringe pump allows us to keep an adjusted concentration of the precursor in the aerosol constant. Tube ovens from Nabertherm were used for the evaporation and the decomposition of the precursor. Exact amounts of gases $\left(\mathrm{N}_{2}\right.$ and $\left.\mathrm{O}_{2}\right)$ are added using mass flow controllers from Bronkhorst (model el-flow select). Typical flow rates are $f_{\text {nitrogen }}=1.2 \mathrm{~L} \mathrm{~min}^{-1}$ and $f_{\text {oxygen }}=0.3 \mathrm{~L} \mathrm{~min}^{-1}$. The precursor concentration is given by the evaporation rate and the volume of the added gases. Typically an evaporation temperature of $90{ }^{\circ} \mathrm{C}$ was selected and the concentration of the precursor could be adjusted in the range of $10^{2}-10^{6} \mu \mathrm{g} \mathrm{m}^{-3}$. Formation of titania takes place in the decomposition zone of the set-up, which is heated to $800{ }^{\circ} \mathrm{C}$. Separation of the $\mathrm{TiO}_{2}$ materials from the aerosol is achieved using a thermophoresis unit. The powder X-ray diffraction pattern of the corresponding material is shown in Fig. 2.

Deposition of mass-selected $\mathrm{Au}_{n}{ }^{-}$. Aerogel-like $\mathrm{TiO}_{2}$ dip-coated (see above) on tantalum plates has been introduced into the deposition chamber of the cluster setup. The chamber was pumped down to $\approx 1 \times 10^{-8}$ mbar and $\mathrm{Au}_{n}{ }^{-}$was deposited onto dip-coated tantalum plates while the neutralization current was measured and integrated to obtain the total number of clusters since they carry a single negative charge. Average deposition currents for the different clusters were 20-100 pA yielding deposition times of several hours. After deposition the samples were removed from the deposition chamber and introduced into another UHV system for XPS analysis.
Cluster deposition setup. The deposition of $\mathrm{Au}_{n}{ }^{-}$cluster ions onto $\mathrm{TiO}_{2}$ dip-coated on tantalum plates will be described in detail here to familiarize the reader with size-selected cluster ion deposition. A gold metal target (gold coin) is vaporized in the cluster ion source (namely: magnetron sputter source, ${ }^{28}$ see Fig. 1) via sputtering with argon ions (see the sputter head and the cluster ion source). The vaporized gold atoms are cooled down by helium carrier gas in the aggregation tube in front of the magnetron sputter head, in turn positive, negative, and neutral clusters are formed and moved in the direction of the differential pumping stages. The sputter- and carrier gas is removed from the cluster (ion) beam via four powerful differential pumping stages. Thereafter negative clusters are accelerated by a guiding voltage of $+1.5 \mathrm{kV}$ to extract negative clusters from the beam. Subsequently, the beam is focused and steered by various ion optics (lenses and "steerers") into a chamber, placed between the pole pieces of a large bending magnet, where, depending on their masses, clusters are deflected by different angles. The neutral clusters are not influenced by the magnetic field and thus are separated from the cluster ion beam. Afterwards the cluster beam should in principle contain only one $\mathrm{Au}_{n}{ }^{-}$species which passes through a cooling trap in order to freeze out any hydrocarbon and hydrosilicon species arising from the operation of diffusion pumps along the cluster beamline. This beam is again focused by ion optics and soft-landed (deposition energies below $1 \mathrm{eV}$ per atom) onto the sample containing dip-coated aerogel-like $\mathrm{TiO}_{2}$ (sample holder). During deposition the negatively charged gold species are neutralized and the resulting current can be measured, an integration of this current yields the charge which in turn can be used to evaluate the number of deposited clusters since clusters typically carry a single negative charge. The mass spectrum of the corresponding $\mathrm{Au}_{n}{ }^{-}$species has been

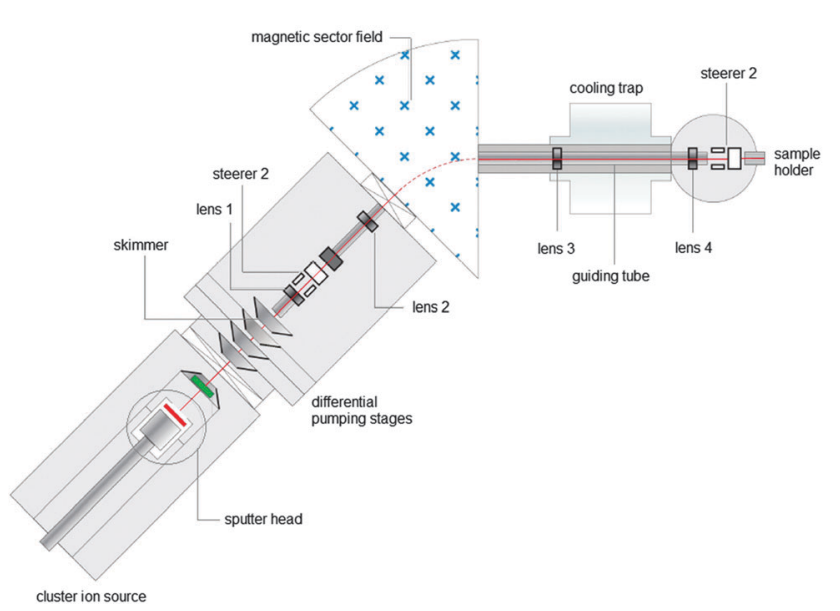

Fig. 1 Cluster beamline used for deposition of small gold clusters onto aerogel-like $\mathrm{TiO}_{2}$. The apparatus consists of a cluster ion source where gold targets are vaporized and clusters are formed. These clusters are transported towards the magnetic sector field via various ion optics in order to be mass-separated. After mass-selection they are steered towards the sample containing $\mathrm{TiO}_{2}$ material and are soft-landed via deceleration by an electric field. 
recorded by sweeping the current of the magnetic field, measuring the corresponding magnetic (B) field using a Hall probe, and the deposition current on a tantalum plate while the sweep is running. A typical mass spectrum in terms of $\mathrm{B}^{2}$ (equidistant peaks) is shown in Fig. 3A and B. Setting the values of the magnetic current to the corresponding ones from the spectrum allows for mass-selection of the cluster ions: $\mathrm{Au}_{4}{ }^{-}$can be regarded as basically a monodisperse cluster, from $\mathrm{Au}_{6}{ }^{-}$the peaks start overlapping, so that $\mathrm{Au}_{7}{ }^{-}$and above are deposited as $\mathrm{Au}_{n \pm 1}{ }^{-}$, and $\mathrm{Au}_{120}{ }^{-}$should be denoted as $\mathrm{Au}_{120 \pm 10}{ }^{-}$which has been omitted for clarity. Deposition currents for gold clusters varied between 20 and 100 pA yielding deposition times of several hours.

\section{Results and discussion}

Aerogel-like $\mathrm{TiO}_{2}$ with a primary particle size of $13.4 \mathrm{~nm}$ has been used as a support material for size-selected gold clusters. The particle size of titania crystallites is determined from the analysis of peak-broadening of the signals obtained by powder X-ray diffraction (PXRD, see Fig. 2) using the Scherrer-method. In addition, TEM micrographs were checked and showed that the size of the $\mathrm{TiO}_{2}$ nanocrystals is in the same region. However, it should be noted that the value obtained from PXRD provides an average size, whereas there is of course a certain polydispersity in the sample.

An innovative approach which permits complementation of real-space techniques for thin-film characterization from reciprocal space is discussed by Perlich et al. ${ }^{29}$ It involves grazing-incidence small-angle X-ray scattering (GISAXS) data and their evaluation. Unfortunately, we do not have any access to SAXS equipment capable of GI-measurements. Therefore, we could only investigate the porosity of the sample by SEM and TEM (which gives only a qualitative impression) and $\mathrm{N}_{2}$ physisorption analysis, which at least gives quantitative figures for internal surface area, pore volume and pore-size distribution. However, giving a precise value for the porosity $\left(\frac{V_{\text {pore }}}{V_{\text {total }}}\right)$ is not possible at the moment. However, it is believed that this is also

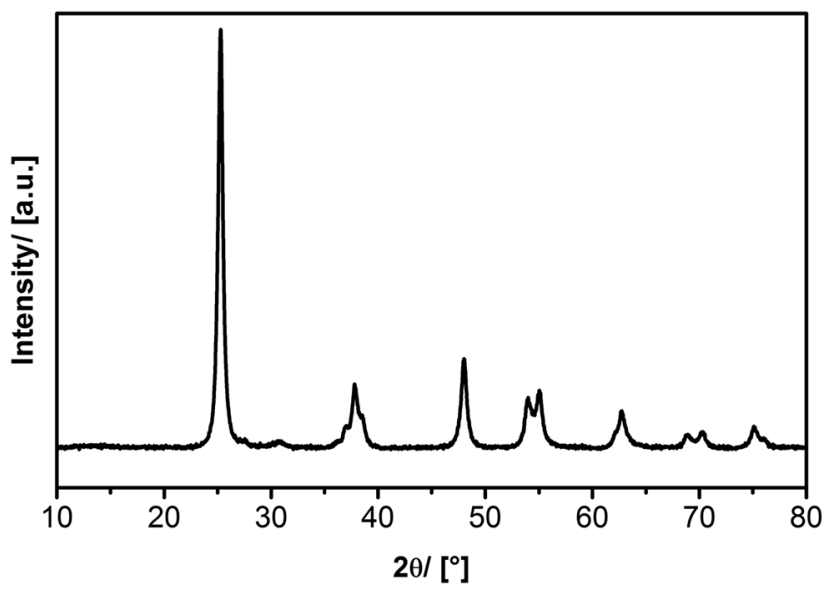

Fig. 2 Powder $\mathrm{X}$-ray diffraction $\left(\mathrm{Cu} \mathrm{K}_{\alpha}\right)$ of titania with a primary particle size of approx. $13 \mathrm{~nm}$ in the anatase phase.
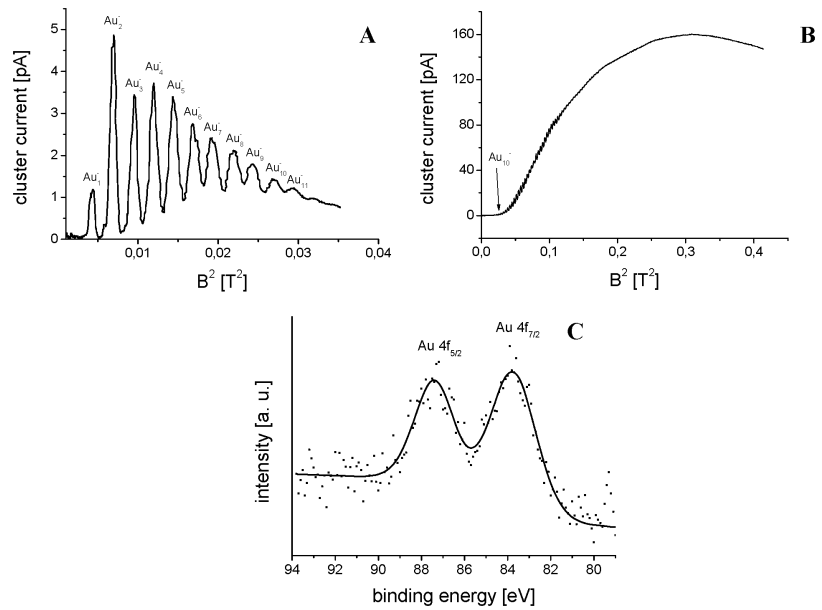

Fig. 3 (A) Mass-spectrum of gold cluster anions in the gas phase as obtained by the magnetic sector field, optimized for small clusters. (B) Mass-spectrum of gold cluster anions in the gas phase without optimization to a specific mass range. (C) XPS region scan of the Au $4 \mathrm{f}$ signals of the composite material $\mathrm{Au}_{120} / \mathrm{TiO}_{2}$.

not critical information for the current contribution, since it is undoubtedly correct that the used, aerogel-like porous $\mathrm{TiO}_{2}$ materials possess high porosity, low density and lots of open pore-space.

The described material has been suspended in ethanol and dip-coated onto tantalum backing plates to facilitate gold cluster deposition. An SEM investigation of the as-prepared plates shows a thickness of $16 \mu \mathrm{m}$ and conserved porosity of the support material (Fig. 4). Furthermore the number of $\mathrm{TiO}_{2}$ particle monolayers can be determined to be about 1200. The film has also been investigated by XPS, however, due to considerable film thicknesses charging effects occur. In order to account for charging $\mathrm{Ti}(+4) 2 \mathrm{p}_{3 / 2}$, which is to be found at $259.0 \mathrm{eV}$, has been used as a reference. ${ }^{27} \mathrm{TiO}_{2} /$ Ta plates have been inserted into a UHV deposition chamber and size-selected gold clusters have been deposited. The mass spectrum of these gold species in the gas phase is presented in Fig. 3A and B. It basically shows monodisperse clusters for small species. Deposition currents for gold clusters varied between 20 and 100 pA yielding deposition times of several hours. Numbers of deposited clusters ranged from $3 \times 10^{11}$ to $8 \times 10^{12}$, which multiplied by " $n$ " yields the number of gold atoms in the sample (see Table 1 ).

A close packed monolayer of gold, e.g., Au(111), contains about $1.5 \times 10^{15}$ atoms per $\mathrm{cm}^{2}$ which in the observed deposition spot (circular with $3 \mathrm{~mm}$ in diameter, $7 \times 10^{-2} \mathrm{~cm}^{2}$ ) translates into $\approx 1 \times 10^{14}$ atoms within the spot per monolayer. The lower limit for detection of surface species by XPS is about $1 \%$ of a monolayer corresponding to $\approx 1 \times 10^{12}$ atoms on the top monolayer of the $\mathrm{TiO}_{2}$ film. For small clusters, especially $\mathrm{Au}_{4}{ }^{-}$, this cannot be achieved since these small clusters are able to penetrate deep into the porous film structure $(\approx 1200 \mathrm{ML})$. The huge number of monolayers in addition to the small amount of gold clusters deposited makes observation of an XPS signal very unlikely, except for the largest clusters, $\mathrm{Au}_{120}{ }^{-}$, which is exactly what is found. In the $\mathrm{Au}_{120} / \mathrm{TiO}_{2}$ composite the number of gold 


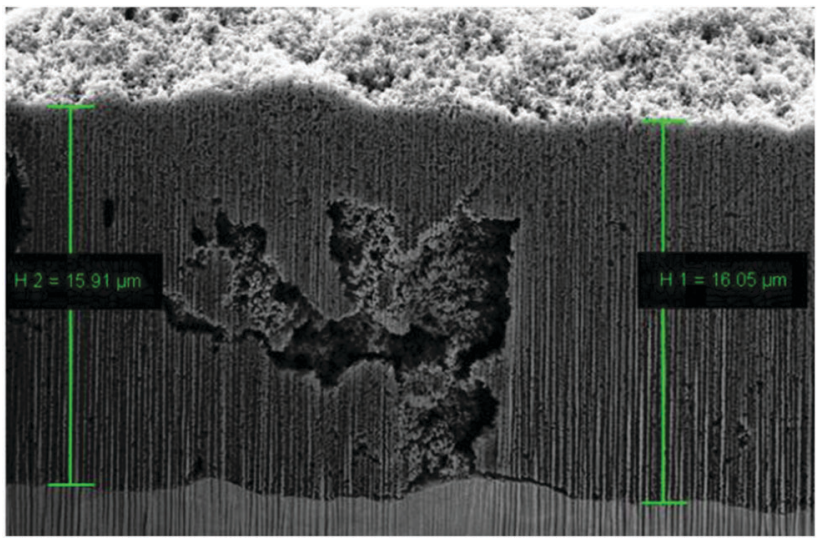

Fig. 4 SEM image of aerogel-like $\mathrm{TiO}_{2}$ dip-coated onto a tantalum backing plate. The thickness has been determined by cross-section and is shown as green bars in the image.

Table 1 Overview of composite materials of type $\mathrm{Au}_{n} / \mathrm{TiO}_{2}$ which have been prepared by size-selected gold cluster deposition onto $\mathrm{TiO}_{2}$ covered tantalum backing plates

\begin{tabular}{llll}
\hline Entry & $\begin{array}{l}\text { Composite } \\
\text { material }\end{array}$ & $\begin{array}{l}\text { Number of } \\
\text { Au clusters }\end{array}$ & $\begin{array}{l}\text { Number of } \\
\text { Au atoms }\end{array}$ \\
\hline 1 & $\mathrm{Au}_{4} / \mathrm{TiO}_{2}$ & $2.7 \times 10^{11}$ & $1.1 \times 10^{12}$ \\
2 & $\mathrm{Au}_{7} / \mathrm{TiO}_{2}$ & $1.3 \times 10^{12}$ & $9.3 \times 10^{12}$ \\
3 & $\mathrm{Au}_{8} / \mathrm{TiO}_{2}(\mathrm{a})$ & $1.9 \times 10^{12}$ & $1.5 \times 10^{13}$ \\
4 & $\mathrm{Au}_{8} / \mathrm{TiO}_{2}(\mathrm{~b})$ & $8.1 \times 10^{12}$ & $6.5 \times 10^{13}$ \\
5 & $\mathrm{Au}_{9} / \mathrm{TiO}_{2}$ & $1.1 \times 10^{12}$ & $1.0 \times 10^{13}$ \\
6 & $\mathrm{Au}_{120} / \mathrm{TiO}_{2}$ & $1.6 \times 10^{12}$ & $1.9 \times 10^{14}$ \\
\hline
\end{tabular}

atoms is about one order of magnitude higher in comparison (see Table 1). On top of that these large clusters might have problems penetrating into the network of $\mathrm{TiO}_{2}$ and unlike the other clusters accumulate on the top $\mathrm{TiO}_{2}$ layer making detection via XPS possible (Fig. 3C). The binding energy after charge correction yields a value of $83.7 \mathrm{eV}$ for $\mathrm{Au} 4 \mathrm{f}_{7 / 2}$ which is close to the bulk value of $84.0 \mathrm{eV}{ }^{27}$ This is to be expected for such big clusters.

The same cross-section SEM technique should in principle be useful to determine the penetration depths of the clusters into the $\mathrm{TiO}_{2}$ layer. The problem with this approach is EDX sensitivity with a lower value of 0.5 to 1 mass $\%$. For samples provided here $1 \mathrm{mg}$ of $\mathrm{TiO}_{2}$ was used which means that $10 \mu \mathrm{g}$ would be needed to be deposited per sample if the cluster ion beam is focused down maybe $1 \mu \mathrm{g}$ or less. On the $\mathrm{Au}_{4}$ sample around $0.4 \mathrm{ng}$ gold was deposited, $3 \mathrm{ng}$ for $\mathrm{Au}_{7}, 5 \mathrm{ng}$ for $\mathrm{Au}_{8}, 3 \mathrm{ng}$ for $\mathrm{Au}_{9}$ and $60 \mathrm{ng}$ for $\mathrm{Au}_{120}$, respectively. Fig. 3B presents a mass spectrum over the complete range of the respective magnetron sputter source which unequivocally shows that larger clusters are much easier to make than smaller ones. So an attempt was made to deposit large clusters in order to achieve enough material to meet EDX sensitivity criteria. $\mathrm{Au}_{120}$ was deposited for $2 \mathrm{~h}$ onto $1 \mathrm{mg}$ of $\mathrm{TiO}_{2}$ suspended in ethanol on a TEM grid which yielded a total amount of approximately $300 \mathrm{ng}$ which was still too low to be detected by EDX, however, the corresponding TEM micrograph of the sample in Fig. 5 demonstrates massive coagulation of these clusters which should not be the case if it was possible for this size to penetrate deeply into the $\mathrm{TiO}_{2}$ network. On the

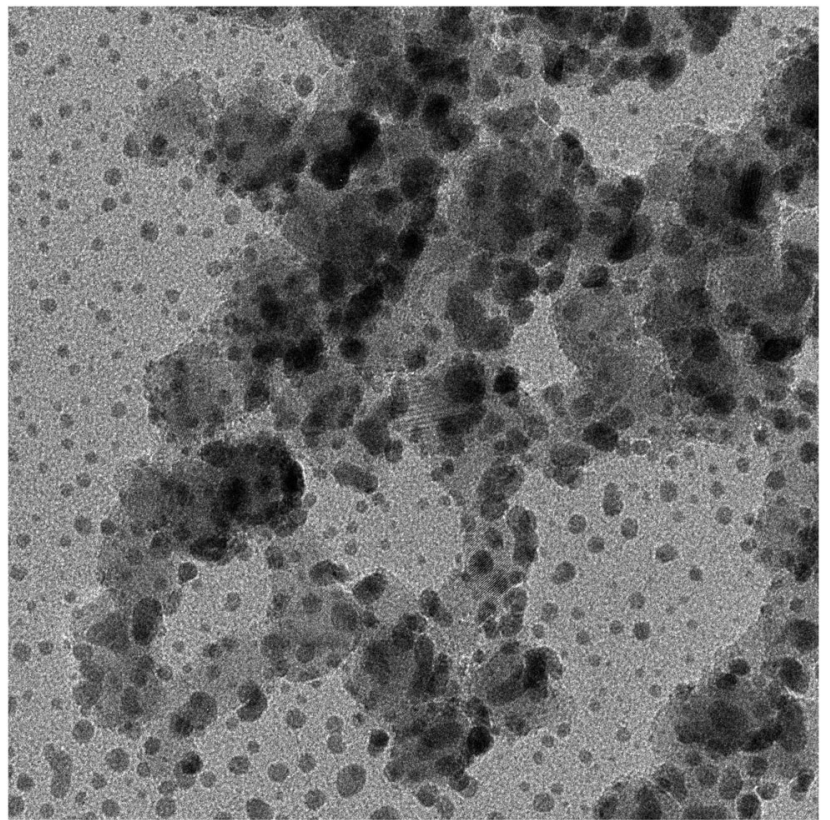

Fig. 5 TEM micrograph of coagulated $\mathrm{Au}_{120}$ clusters on $\mathrm{TiO}_{2}(162.5 \mathrm{~nm} \times$ $162.5 \mathrm{~nm}$ ) obtained at the boundaries of the $\mathrm{TiO}_{2}$ spot. Massive coagulation is observed which should be prevented in case of the penetration into the titania network. The predicted size of clusters from the gas phase is approximately $2 \mathrm{~nm}$ but sizes from 5 to $30 \mathrm{~nm}$ are observed here.

other hand it was not possible to find any evidence for smaller clusters within TEM micrographs due to their very low mass and deposition currents. We believe these measurements tentatively show the low penetration depths of large $\mathrm{Au}_{120}$ clusters into the titania framework.

Composite materials presented in Table 1 have been used as catalysts for the bromination of 1,4-dimethoxybenzene (1) using NBS (2). The $\mathrm{Au}_{n} / \mathrm{TiO}_{2}$ materials were removed from the tantalum backing plate and transferred directly into reaction vessels containing 1 and 2 dissolved in dichloroethane which have been stirred for $24 \mathrm{~h}$ at room temperature (see the Experimental section). The conversion of the reaction has been checked via gas chromatography. The results are found in Table 2. Compared to previous results ${ }^{11,30}$ achieved TONs with size-selected gold clusters on titania are extremely high, while a TON of $10^{2}$ is described in the literature TONs as high as $10^{8}$ are found for $\mathrm{Au}_{7} / \mathrm{TiO}_{2}$ (Table 2, entry 6, Fig. 6). This gap in TON should be ascribed to the "naked" nature of the clusters obtained by "soft-landing" in UHV compared to size-selected clusters created by dendrimer templates. Clusters formed within a dendrimer become encapsulated in the template which acts as a large ligand with multiple binding sites ${ }^{12,13}$ preventing leaching into solution but also decreasing exposure to reactants. A closer look shows that composite materials $\mathrm{Au}_{n} / \mathrm{TiO}_{2}(n=4,7,9)$ exhibit similar TONs based on the number of gold atoms (Table 2, entries 5, 6, 9 and Fig. 6) which might be indicative of dissolution of clusters into the reactant solution facilitating behavior as described by J. Oliver-Meseguer et al. ${ }^{11}$ Due to its $\mathrm{d}^{10} \mathrm{~s}^{1}$ valence electron configuration gold is considered a "simple" metal and can be treated by the Jellium model, ${ }^{31}$ according to which $\mathrm{Au}_{4}, \mathrm{Au}_{7}$, 
Table 2 Catalytic results for the bromination of 1,4-dimethoxybenzene (A) using NBS (B) via $\mathrm{Au}_{n} / \mathrm{TiO}_{2}$ composite materials

\begin{tabular}{|c|c|c|c|c|}
\hline OM & $\pi_{0}^{N-}$ & $\begin{array}{c}\text { catalyst } \\
\underset{\text { dichloromethane }}{24 \mathrm{~h}}\end{array}$ & OMe & + \\
\hline Entry & Catalyst & Conversion $[\%]$ & $\begin{array}{l}\text { TON per gold } \\
\text { cluster }^{c}\end{array}$ & $\begin{array}{l}\text { TON per gold } \\
\text { atom }^{d}\end{array}$ \\
\hline 1 & None (blank) & $\approx 0$ (Trace amounts) & 0 & 0 \\
\hline 2 & $\mathrm{AuCl}^{a}$ & $\approx 100$ & Undefined & 23 \\
\hline 3 & $\mathrm{HAuCl}_{4}{ }^{a}$ & $\approx 100$ & Undefined & 33 \\
\hline 4 & $\mathrm{TiO}_{2}{ }^{a}$ & $\approx 0$ (Trace amounts) & 0 & 0 \\
\hline 5 & $\mathrm{Au}_{4} / \mathrm{TiO}_{2}{ }^{b}$ & 4.4 & $5.1 \times 10^{7}$ & $1.3 \times 10^{7}$ \\
\hline 6 & $\mathrm{Au}_{7} / \mathrm{TiO}_{2}^{b}$ & 52.0 & $1.2 \times 10^{8}$ & $1.7 \times 10^{7}$ \\
\hline 7 & $\mathrm{Au}_{8} / \mathrm{TiO}_{2}(\mathrm{a})^{b}$ & 3.2 & $5.1 \times 10^{6}$ & $6.4 \times 10^{5}$ \\
\hline 8 & $\mathrm{Au}_{8} / \mathrm{TiO}_{2}(\mathrm{~b})^{b}$ & 16.0 & $6.5 \times 10^{6}$ & $8.1 \times 10^{5}$ \\
\hline 9 & $\mathrm{Au}_{9} / \mathrm{TiO}_{2}{ }^{b}$ & 46.0 & $1.3 \times 10^{6}$ & $1.4 \times 10^{7}$ \\
\hline 10 & $\mathrm{Au}_{120} / \mathrm{TiO}_{2}^{b}$ & 20.0 & $3.6 \times 10^{7}$ & $3.0 \times 10^{5}$ \\
\hline
\end{tabular}

${ }^{a} 5 \mathrm{mg}$ was added. $^{b} 1 \mathrm{mg}$ was $\operatorname{added}^{c} \mathrm{In}$ units of $\frac{\text { number of molecules } \mathbf{C}}{\text { number of gold clusters }}{ }^{d}$ In units of $\frac{\text { number of molecules } \mathbf{C}}{\text { number of gold atoms }}$.

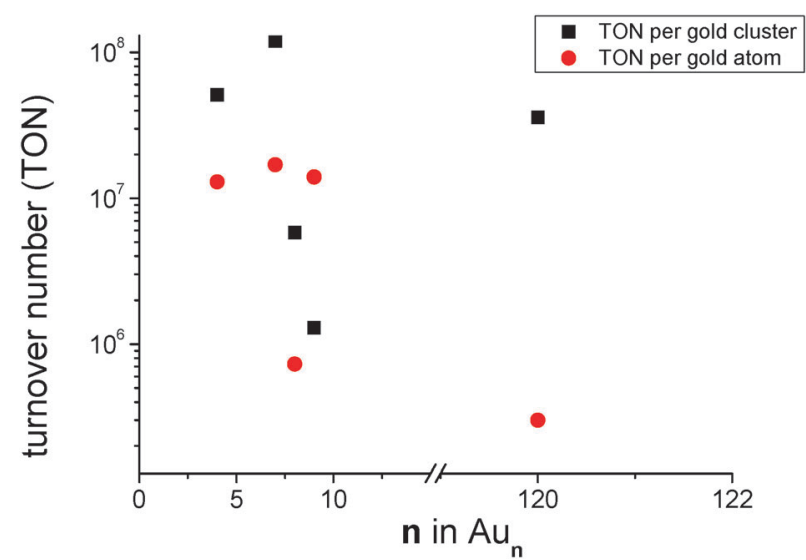

Fig. 6 Graphical representation of the content of Table 2 showing the TON per gold cluster (squares) and the TON per gold atom (filled circles) plotted against the number of atoms in the cluster for $\mathrm{Au}_{4} / \mathrm{TiO}_{2}, \mathrm{Au}_{7} / \mathrm{TiO}_{2}, \mathrm{Au}_{8} / \mathrm{TiO}_{2}$, and $\mathrm{Au}_{9} / \mathrm{TiO}_{2}$ in units of $\frac{\text { number of molecules } \mathbf{C}}{\text { number of gold clusters }}$ and $\frac{\text { number of molecules } \mathbf{C}}{\text { number of gold atoms }}$, respectively. Most striking is the difference in TON per gold atom between $n=8$ and 120 and $n=4,7,9$.

and $\mathrm{Au}_{9}$ do not exhibit any particular stability and thus are prone to show this type of behavior. On the other hand $\mathrm{Au}_{8}$ (Table 2, entries 7 and 8 and Fig. 6) is a very stable magic number cluster completely filling the 1 p cluster valence orbital and indeed the TON per atom is two orders of magnitude lower compared to the previous examples. This is indicative of a stable cluster which remains on the surface (in the pores) giving rise to less exposure to reactant molecules and in turn lower TONs per gold atom. The large $\mathrm{Au}_{120}$ clusters have similar low TONs per gold atom which can be blamed on the reduced solubility of larger clusters compared to smaller ones (no particular stability according to the Jellium model).

Direct sputter deposition from a target onto a substrate does not allow the landing of intact monodisperse pre-formed entities from the gas-phase onto the sample contrary to softlanding of size-selected particles. It has to be admitted that sputter deposition is much easier to be conducted and much faster than the latter method. Moreover, the ingenious method of GISAXS is able to characterize film growth under sputter conditions in real-time, results obtained by Schwartzkopf et $a .^{32}$ show four-stage growth and the corresponding thresholds with submonolayer resolution. This knowledge allows tremendous control over film properties and cluster size in the nanometer range. Work conducted by Valden et $a l .{ }^{33}$ shows that gold catalysts on titania for $\mathrm{CO}$ oxidation at exposure times of 10 Torr $\mathrm{CO}: \mathrm{O}_{2}(2: 1)$ for $120 \mathrm{~min}\left(7.2 \times 10^{10} \mathrm{~L}\right)$ show best reaction rates for islands with a diameter between 2.5 and $3.5 \mathrm{~nm}$. These islands show a thickness of only two layers and their activity is blamed on the high aspect ratio and related quantum size effects introducing a band-gap into these islands. Employing the GISAXS method should facilitate exceptionally simple preparation of CO oxidation catalysts in this pressure regime. However, if the reactant exposure is lowered down to $0.2-600 \mathrm{~L}$ only clusters $\mathrm{Au}_{6}$ and $\mathrm{Au}_{7}$ show catalytic activity on $\mathrm{TiO}_{2}$ which was presented in a recent contribution (see above), ${ }^{16}$ i.e., indeed every atom counts. Larger and smaller clusters would be a waste of gold under such conditions. Similar results were found by J. Oliver-Meseguer et al. for the bromination of aromatics using gold clusters in solution as described above. Although sputter deposition of gold clusters is unmatched in simplicity and duration for the physical preparation of heterogeneous gold catalysts it is believed that the full potential of the non-scalable sub-nano regime can only be exploited by size-selected cluster deposition under softlanding conditions so far.

\section{Conclusions}

Sharp size-dependencies for catalytic activities are well-known from reactions under UHV conditions with size-selected cluster catalysts, ${ }^{14-16,34,35}$ and only experiments involving size-selected deposition made it fashionable to think of the exact number of atoms in heterogeneous catalysis. Here it could be shown that the "pressure gap" can be overcome for "soft-landed" gold clusters on $\mathrm{TiO}_{2}$ which act as very efficient bromination catalysts in solution under "real" catalytic conditions. Since sharp size-dependence is also observed and can be explained in terms of the Jellium model. In conclusion size-selected cluster deposition presents an invaluable tool to facilitate deliberate creation of active sites in heterogeneous catalysis which is the idea of nanocatalysis. ${ }^{17}$ As future steps deposition currents for gold clusters have to be optimized to synthesize sufficient amounts for in-depth mechanistic analysis of catalytic reactions.

\section{Acknowledgements}

Financial support from the German research foundation (DFG) is gratefully acknowledged (Grant No.: GA 389/24-1 and PO 780/8-1). 


\section{Notes and references}

1 G. J. Hutchings, J. Catal., 1985, 96, 292-295.

2 M. Haruta, T. Kobayashi, H. Sano and N. Yamada, Chem. Lett., 1987, 405-408.

3 M. D. Hughes, Y. J. Xu, P. Jenkins, P. McMorn, P. Landon, D. I. Enache, A. F. Carley, G. A. Attard, G. J. Hutchings, F. King, E. H. Stitt, P. Johnston, K. Griffin and C. J. Kiely, Nature, 2005, 437, 1132-1135.

4 A. Grirrane, A. Corma and H. Garcia, Science, 2008, 322, 1661-1664.

5 M. Turner, V. B. Golovko, O. P. H. Vaughan, P. Abdulkin, A. Berenguer-Murcia, M. S. Tikhov, B. F. G. Johnson and R. M. Lambert, Nature, 2008, 454, 981-983.

6 A. A. Herzing, C. J. Kiely, A. F. Carley, P. Landon and G. J. Hutchings, Science, 2008, 321, 1331-1335.

7 A. S. K. Hashmi, Chem. Rev., 2007, 107, 3180-3211.

8 Y. Oh, D. Gros, C. Alcidi and P. de Grauwe, Economic Policy, CEPS Special Reports, 2010.

9 H. S. Taylor, Proc. R. Soc. London, Ser. A, 1925, 108, 105-111.

10 G. J. Hutchings, Gold Bull., 2009, 42, 260-266.

11 J. Oliver-Meseguer, J. R. Cabrero-Antonino, I. Dominguez, A. Leyva-Perez and A. Corma, Science, 2012, 338, 1452-1455.

12 J. Zheng, C. W. Zhang and R. M. Dickson, Phys. Rev. Lett., 2004, 93, 077402.

13 K. Yamamoto, T. Imaoka, W. J. Chun, O. Enoki, H. Katoh, M. Takenaga and A. Sonoi, Nat. Chem., 2009, 1, 397-402.

14 S. S. Lee, C. Y. Fan, T. P. Wu and S. L. Anderson, J. Am. Chem. Soc., 2004, 126, 5682-5683.

15 S. Lee, C. Y. Fan, T. P. Wu and S. L. Anderson, J. Chem. Phys., 2005, 123, 124710.

16 X. Tang, J. Schneider, A. Dollinger, Y. Luo, A. S. Worz, K. Judai, S. Abbet, Y. D. Kim, G. F. Gantefor, D. H. Fairbrother, U. Heiz, K. H. Bowen and S. Proch, Phys. Chem. Chem. Phys., 2014, 16, 6735-6743.

17 R. Schlögl and S. B. Abd Hamid, Angew. Chem., Int. Ed., 2004, 43, 1628-1637.
18 S. Dilger, C. Hintze, M. Krumm, C. Lizandara-Pueyo, S. Deeb, S. Proch and S. Polarz, J. Mater. Chem., 2010, 20, 10032-10040.

19 S. Dilger, C. Lizandara-Pueyo, M. Krumm and S. Polarz, Adv. Mater., 2012, 24, 543-548.

20 D. Lehr, D. Grossmann, W. Gruenert and S. Polarz, Nanoscale, 2014, 6, 1698-1706.

21 D. C. Lim, R. Dietsche, M. Bubek, G. Ganteför and Y. D. Kim, ChemPhysChem, 2006, 7, 1909-1911.

22 D. C. Lim, R. Dietsche, G. Gantefor and Y. D. Kim, Chem. Phys. Lett., 2008, 457, 391-395.

23 D. C. Lim, R. Dietsche, G. Gantefor and Y. D. Kim, Chem. Phys., 2009, 359, 161-165.

24 D. C. Lim, R. Dietsche, G. Ganteför and Y. D. Kim, Appl. Surf. Sci., 2009, 256, 1148-1151.

25 D. W. Goodman, Catal. Lett., 2005, 99, 1-4.

26 M. Boronat, A. Leyva-Pérez and A. Corma, Acc. Chem. Res., 2014, 47, 834-844.

27 J. F. Moulder, W. F. Stickle, P. E. Sobol and K. D. Bomben, Handbook of X-ray photoelectron spectroscopy, Physical Electronics, Inc., 1995.

28 H. Haberland, M. Karrais, M. Mall and Y. Thurner, J. Vac. Sci. Technol., A, 1992, 10, 3266-3271.

29 J. Perlich, G. Kaune, M. Memesa, J. S. Gutmann and P. MüllerBuschbaum, Philos. Trans. R. Soc., A, 2009, 367, 1783-1798.

30 F. Mo, J. M. Yan, D. Qiu, F. Li, Y. Zhang and J. Wang, Angew. Chem., Int. Ed., 2010, 49, 2028-2032.

31 W. A. de Heer, Rev. Mod. Phys., 1993, 65, 611-676.

32 M. Schwartzkopf, A. Buffet, V. Korstgens, E. Metwalli, K. Schlage, G. Benecke, J. Perlich, M. Rawolle, A. Rothkirch, B. Heidmann, G. Herzog, P. Muller-Buschbaum, R. Rohlsberger, R. Gehrke, N. Stribeck and S. V. Roth, Nanoscale, 2013, 5, 5053-5062.

33 M. Valden, X. Lai and D. W. Goodman, Science, 1998, 281, 1647-1650.

34 W. E. Kaden, T. P. Wu, W. A. Kunkel and S. L. Anderson, Science, 2009, 326, 826-829.

35 Y. Watanabe, X. Wu, H. Hirata and N. Isomura, Catal. Sci. Technol., 2011, 1, 1490-1495. 